\title{
OREVER|
}

\section{A Gestão Rural e o desafio contemporâneo informacional da Produção Leiteira}

\section{Rural Management and the contemporary informational challenge of Dairy Production}

\section{Leandro Gabriel Flamino}

flamino.leo@gmail.com

Graduando em Ciências Econômicas na Universidade Federal de Santa Maria (UFSM), campus Palmeira das Missões.

\section{Luanderson Centenaro Borges}

luanderson.borges@br.nestle.com

Graduando em Zootecnia pela Universidade Tecnológica Federal do Paraná (UTFPR), campus Dois Vizinhos.

Recebido em: 18/10/2018

Aprovado em: 22/04/2019
Revista do Programa de Pós-Graduação em Extensão Rural (UFV) 


\title{
OREVER
}

\section{RESUMO}

O estudo teve como objetivo analisar a gestão do empreendimento rural de produção leiteira. Assim, foram avaliados a gerência rural e o uso de ferramentas administrativas, zootécnicas e econômicas na produção de leite, a fim de revelar a importância de se observar a unidade de produção rural como empresa. Para tanto, o método utilizado se pautou em revisão bibliográfica. Os resultados apontaram que a fusão de conhecimentos da administração rural com os zootécnicos e econômicos produz informações elementares importantes para a tomada de decisão, que é de suma importância para a sustentação da atividade leiteira. $\mathrm{O}$ estudo mostrou que, para produzir com eficiência, deve-se conhecer todo o processo produtivo, bem como controlá-lo, para poder gerir resultados de produção com qualidade e menos custos.

Palavras-Chave: Gestão Rural; Desafios da Gestão Rural; Produção de Leite.

\begin{abstract}
The study evaluates the rural management and the use of administrative, zootechnical and economics tools in dairy production. Reveals the importance of observing the unity of rural dairy production as a company. The objective was to understand the management of the rural enterprise of dairy production. Becomes aware that the informational use an essential for improving managerial health. Thus, the method used was bibliographic review. The results indicate that the fusion of knowledges of the rural administration with the zootechnical and economics ones produces elementary information for decision making that is of paramount importance to sustain the dairy activity. It is concluded that in order to produce efficiently, one must know the entire production process and also control it for can manage the production results with quality and less costs.
\end{abstract}

Keywords: Rural Management; Challenges of Rural Management; Milk Production. 


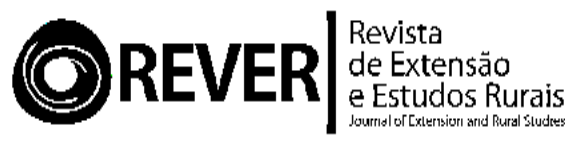

\section{Introdução}

De acordo com o Departamento de Agricultura dos Estados Unidos (United States Department of Agriculture - USDA), a projeção do Brasil no ranking mundial de produção de leite, no ano de 2017, era de manter a ocupação na quinta posição, atrás de União Europeia; Estados Unidos; Índia e China, respectivamente (CONAB, 2016).

Segundo o Instituto Brasileiro de Geografia e Estatística (IBGE), a Empresa Brasileira de Pesquisa Agropecuária (Embrapa) e o Ministério da Agricultura, Pecuária e Abastecimento (MAPA), a previsão para o ano de 2017 era de que o Brasil chegaria a produzir algo em torno de 35 bilhões de litros de leite (CONAB, 2017). Já para o MAPA (2011) e a Organização das Nações Unidas para Alimentação e Agricultura (FAO) (2016), a perspectiva é de contínuo crescimento da produção, atingindo algo em torno de 38,2 bilhões de litros de leite ao final de 2020/2021 (apud WILBERT et al., 2016, p. 393).

Considerando a posição no ranking mundial quanto ao número de vacas leiteiras em 2014, o Brasil ocupou a segunda colocação, com cerca de 39 milhões de animais, e ficou somente atrás da Índia, com 130 milhões, onde, devido a suas especificidades culturais, a vaca é considerada um símbolo sagrado, não havendo, portanto, abatimento do animal no país (SEAB, 2016).

De acordo com as pesquisas da Embrapa Gado e Leite, o número do rebanho brasileiro de vacas ordenhadas, em 2010, girou em torno de 23 milhões de animais (ZOCCAL, 2012). Segundo o Sidra (Sistema do IBGE de Recuperação Automática), em 2016, foram registrados 19,7 milhões de vacas ordenhadas no Brasil (IBGE, 2017). Contudo, mesmo diante dessa redução, a capacidade produtiva de leite aumentou nesse curto período mencionado, sendo o aumento da produtividade animal um indicador importante de competitividade, o que não é novidade na comparação entre Produção de Leite e Efetivo de Animais Ordenhados, no país, desde o ano de 1996 (BNDES, 2009).

Segundo o IBGE, em 2012, tinha-se 1,3 milhões de unidades produtivas de leite no Brasil, respondendo por $25 \%$ dos estabelecimentos rurais totais, sendo registrada a atividade leiteira em 99\% dos municípios brasileiros (ZOCCAL, 2012). O crescimento do mercado de lácteos, entre o ano de 2010 e 2016, foi de 204\%, enquanto seu faturamento chegou a atingir um valor bruto de R \$ 67,5 bilhões em 2016 (FORMIGONI, 2017).

A atividade leiteira é uma das mais complexas do setor agropecuário, visto que a tomada de decisão envolve aspectos técnicos e econômicos, para a qual se exige dos 


\section{OREVER/|}

produtores preparo técnico e gestão empresarial (BUENO, 2013 apud DA SILVA et al., 2015 p. 64).

Segundo Reichert (1998), conforme citado por Martins (2014, p. 23), o ato de gerenciar um estabelecimento rural torna-se de fundamental importância, senão elementar, na busca de um desenvolvimento financeiro sustentável para a propriedade. De acordo com Machado e Meneghini (2011), um estabelecimento leiteiro pode ser considerado modelo de empresa bem-sucedida e bem gerenciada, caso apresente bons resultados em relação aos indicadores zootécnicos, administrativos e financeiros/econômicos.

Pode-se tratar os indicadores como um tripé, e quando bem gerenciados -de modo eficiente --, fazem com que o estabelecimento produtor de leite seja direcionado à eficácia. Os indicadores zootécnicos tratam como objeto o rebanho leiteiro, o qual é o principal patrimônio da propriedade do ponto de vista econômico. Já os indicadores administrativos, vão além de índices relacionados aos ciclos desse patrimônio, pois tratam também das capacidades e habilidades dos colaboradores, bem como dos parâmetros relacionados com o mercado. Por fim, indicadores financeiros abordam como objeto o capital envolvido em todas as etapas do processo produtivo leiteiro (VALLÉ S.A., 2014).

De acordo com Godinho (2015), as aplicações de tais ferramentas administrativas não garantem o sucesso pleno de um sistema de gestão. É preciso exercer influência na gestão de pessoas, para que executem o planejamento traçado de acordo com suas habilidades específicas. Isso depende de um bom planejamento, fundamentado em dados e informações escrituradas. Portanto, torna-se grande o desafio de executar uma gestão contemporânea aplicada aos estabelecimentos rurais produtores da cadeia leiteira.

Dada a relevância do leite para o agronegócio brasileiro, expressada brevemente em números e comparações, faz-se necessária uma averiguação sobre a contextualização contemporânea do setor. Em consonância com a maneira pela qual as gestões das propriedades leiteiras voltam-se para o correto entendimento e uso do termo gerenciamento, considerando a visão de aproveitamento, é que os resultados são perseguidos - conforme adequada execução gerencial -, podendo proporcionar aspectos positivos para os estabelecimentos do agronegócio leiteiro. Assim, é possível contribuir para que os resultados regionais, e consequentemente brasileiros, alcancem marcos de notória expressão no ramo de atividade.

Para atingir o objetivo de elucidar a maneira pela qual tal gestão é executada, o presente estudo busca, entre outros assuntos, compreender de que jeito os modelos de 


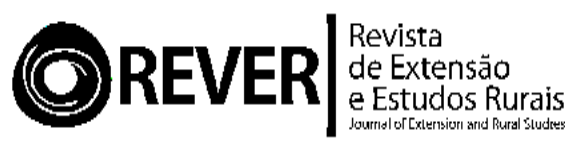

gestão podem vir a se tornarem eficientes. Trata-se de enxergar tais estabelecimentos produtores de leite como empresas ou, simplesmente, estabelecimento rural-empresa, buscando executar com diligência o gerenciamento empresarial.

O objetivo principal do estudo é possibilitar o entendimento quanto à maneira de gerir o empreendimento rural de produção leiteira, além de explorar a conscientização do uso da gestão rural informacional.

\section{Metodologia}

O método empregado no presente estudo é o de pesquisa exploratória. Parte-se da busca e da revisão da literatura disponível sobre o assunto, sendo adotadas etapas de: pesquisa de publicações já consolidadas; coleta de informações através de leitura exploratória e, posteriormente, leitura seletiva; análise e interpretação desses textos; e, por fim, seleção dos textos obtidos.

Vencida essa parte, entendeu-se que o estudo tomou um escopo de revisão bibliográfica. De acordo com Marconi e Lakatos (1992), a pesquisa bibliográfica é o ato de levantamento e apuração, mirando bibliografias publicadas em forma de livros, artigos de revistas, imprensa escrita, dissertação, teses, repositórios digitais de universidades, páginas especializadas no assunto e outros documentos, impressos ou eletrônicos, que, no âmbito deste estudo, viabilizaram a verificação de informações e a coleta de textos para o desenvolvimento do presente trabalho.

\section{Gestão e o modo aplicado na produção leiteira}

Para Wilbert et al. (2016), os ambientes de produção leiteira que trabalham com um produto de concorrência perfeita e de alta intensidade concorrencial demandam tomadas de decisões baseadas em ações estratégicas.

As ações estratégicas visam à sustentabilidade e ao estabelecimento de uma posição definida no mercado praticado e se traduzem nos planejamentos e estratégias competitivas tomadas pelo gestor do estabelecimento (PORTER, 1999; PETTER; RESENDE; CERANTO, 2011, apud WILBERT et al, 2016 p. 392). Aqueles que ajustam mais rapidamente sua estratégia de realocação de seus recursos desfrutam das oportunidades do mercado primeiro que os concorrentes.

Para serem considerados modelos de empresas leiteiras bem gerenciadas, os estabelecimentos devem alcançar bons índices zootécnicos, administrativos e financeiros. De forma organizada, busca-se documentar o máximo de informações acerca de 


\section{OREVER|}

resultados e procedimentos voltados para uma adequada gestão de negócios, na qual pode-se, então, mensurar o desempenho de um estabelecimento produtor de leite, possibilitando tomadas de decisões coerentes, baseadas em números, índices e gráficos confeccionados a partir dos dados coletados (MACHADO; MENEGHINI, 2011).

Segundo Vilckas (2005, apud BORTOLINI, 2010, p 16), para que o produtor desenvolva e acompanhe a evolução do estabelecimento rural, é de fundamental importância que sua propriedade seja administrada como uma empresa. Para tanto, devese adotar técnicas e procedimentos gerenciais adequados à sua realidade. Entre esses procedimentos, destacam-se o planejamento das práticas produtivas, cujo objetivo é tornar a empresa mais eficiente e competitiva, assim como as necessárias e pontuais tomadas de decisões envolvidas na atividade leiteira.

Conforme Yamaguchi e Carneiro (1997, apud LOPES et. al., 2000 p. 01 e 02), o produtor de leite precisa quebrar o velho paradigma tradicional de gestão e adotar uma nova visão em relação à administração de seus negócios, passando, então, de uma posição convencional para a apropriação de um papel mais moderno, o de empresário rural.

Mudanças na atividade ocorrerão quando produtores de leite transformarem suas percepções e enxergarem seu estabelecimento como um empreendimento, e, assim, condicionarem um gerenciamento moderno na prática, que faça uso de sistemas de controles eficientes em todo o seu know-how produtivo, permitindo, então, avaliações periódicas dos processos, em busca de melhorias contínuas para a sua empresa rural de atividade leiteira (SILVA, 2000).

Há um movimento nacional para fazer com que a atividade agropecuária do setor leiteiro reconheça a necessidade de mudanças em seus estabelecimentos rurais que se encontram sob a forma do modelo vigente. A condução técnica e gerencial - apoiada na visão de entrega da qualidade do produto -, mesmo que ainda tímida, busca levar adiante o emprego da prática de uma filosofia gerencial moderna e de entrega de qualidade, a qual serve para toda e qualquer atividade leiteira (SILVA, 2000).

Apontamentos favoráveis à prática de uma nova filosofia gerencial no setor agropecuário leiteiro - tal como a adesão a programas de qualidade -, são considerados, também, uma questão estratégica para alavancar o segmento, simplesmente em virtude da busca de uma implementação gerencial eficiente e moderna, que, ao elevar a atividade leiteira para uma posição privilegiada, propicia a entrega, através da porteira, por exemplo, da produção de alimentos de alta qualidade (SILVA, 2000). 


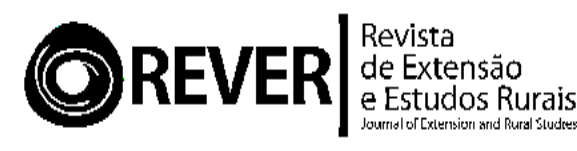

Por meio da adesão a um gerenciamento moderno, é esperado que os custos se tornem inferiores e, do ponto de vista macroeconômico - mesmo que isso seja reflexo da produção em larga escala no Brasil, país essencialmente agrícola por vocação, que detém larga extensão produtiva no ramo de atividade -, o ir ao encontro de uma prática da gestão moderna faz com que os resultados nacionais sejam notórios e relevantes mundialmente (SILVA, 2000).

Mesmo com benefícios dos programas de qualidade para o setor, ainda há poucos casos práticos de uso dessa filosofia administrativa (SILVA, 2000). Contudo, a preocupação com a produção de leite de qualidade atravessa tentativas de movimentar melhorias na produção, mediante a observância das Instruções Normativas n 51/2002 e $n^{\circ}$ 62/2011, que estabelecem prazos e padrões de qualidade para o leite (MAPA, 2014), o que eleva o cuidado com a gestão dos estabelecimentos produtores.

De modo geral, a gestão da produção leiteira é de fundamental importância, uma vez que permite ao produtor um potencial conhecimento de questões referentes à propriedade como um todo, bem como possibilita a maximização do controle dos fatores internos da unidade produtiva (PARIS et. al., 2012).

De acordo com Paris et. al. (2012), é através de registros sistemáticos que se controla as atividades, analisa-se resultados e planeja-se as ações e decisões necessárias. Acompanhando os custos de produção, pode-se ampliar a visão gerencial para analisar, via indicadores, a rentabilidade da atividade e a redução desses custos, elementos importantes para o processo de tomada de decisões de forma segura, objetiva e correta.

Para Pedra (2008, apud ARAÚJO, 2016, p. 17), no caso da cadeia produtiva de leite, os registros sistemáticos mais simples e mais usados, em aspecto geral, se dá em três etapas: (a) "antes da porteira” (insumos agropecuários, maquinário, água, energia, etc.); (b) "dentro da porteira” (atividade pecuária voltada para a produção láctea); e (c) “depois da porteira" (processamento, formação de preço e comercialização do produto).

Um estudo desenvolvido por Cassanego Jr. et al. (2018) utilizou temáticas de redes e cadeia de suprimento e analisou os relacionamentos estruturais e relacionais da cadeira produtiva de leite. As medidas de avaliação e os níveis de confiança utilizados no estudo identificaram determinados aspectos, como o posicionamento dos agentes e a configuração da rede. Essas análises fornecem suporte à tomada de decisões em nível de gestão para "antes da porteira" e "depois da porteira".

Segundo Yamaguchi e Carneiro (1997, apud LOPES, 2016, p. 21), pela quantidade de informações geradas em um estabelecimento rural de produção, as decisões 


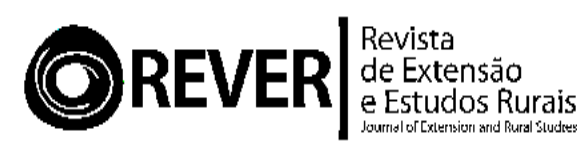

não podem ser tomadas somente com base na experiência do gestor e/ou no conhecimento momentâneo da situação, portanto, a gestão aplicada de forma sistemática e adequada deve ser executada de maneira clara e consciente.

Sendo assim, julga-se que o produtor rural necessita visualizar sua unidade de produção leiteira como um empreendimento, ou seja, como um estabelecimento ruralempresa. E como tal, deve-se adotar algumas ferramentas de gestão, administrativas, zootécnicas e financeiras, a fim de auxiliá-lo a gerenciar da melhor forma o seu negócio.

\section{O gestor moderno e a atividade rural}

A gestão empresarial é um processo que traceja concretizar objetivos organizacionais bem definidos onde, mediante gestão de pessoas e recursos disponíveis, se realizam as atividades. As principais funções a serem desempenhadas pelo gestor são: planejamento, implementação e controle das atividades.

Segundo Bateman e Snell (1998), o ato de planejar tem a função de direcionar claramente os objetivos a serem perseguidos, bem como possibilitar a execução adequada dos processos de ações, no intuito de atingir determinado escopo. Sobre implementar um modelo de gestão, entende-se por executar ações que, previamente identificadas e planejadas, deverão ser coordenadas, de acordo com os recursos disponíveis, valendo-se das atribuições do gestor, que são: controlar; assegurar que os objetivos almejados possam ser atingidos com sucesso durante todo o processo; e monitorar atividades de execução para estabelecer possíveis ações corretivas, caso sejam necessárias.

Percebe-se a necessidade, por parte dos empresários rurais, de aderir a modelos de gestão administrativa que os apoiem no processo de tomada de decisões. Uma vez englobados por processos de gestão que os auxiliam nas tomadas de decisões, entendem que o fato de a produção leiteira atender os padrões de exigência do mercado consumidor é condição elementar para a inserção de um empreendimento rural em uma cadeia produtiva bem coordenada. Portanto, a administração rural é vista como uma área do conhecimento fundamental para auxiliar a transformação de um empreendimento tradicional em um empreendimento de gestão moderna (NANTES \& SCARPELLI, 2007).

Para ocorrer mudanças nos processos de gestão e controle, é necessário que haja formas de escrituração ou anotações de eventos zootécnicos e econômicos ocorridos, documentos básicos para o gerenciamento adequado da atividade leiteira. 


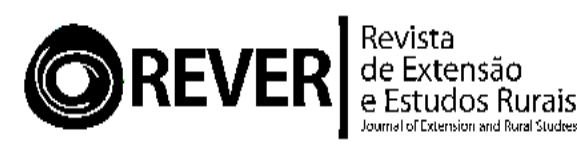

Para Lourenzani, Souza Filho e Bànkuti (2012), tais processos, atrelados ao maior conhecimento possível sobre a estrutura e o funcionamento do próprio estabelecimento leiteiro, bem como acerca dos fatores de produção, retornarão melhores chances de sofisticar os indicadores do tripé, a saber: administrativos; financeiros/econômicos; e de pessoas. Esses indicadores são os que mostrarão em que marco se encontra a propriedade e em que direção ela deve seguir para se alcançar melhorias.

Para Araújo (2016), o gestor do empreendimento rural deve coletar dados, gerar informações, tomar decisões e realizar ações advindas dessas deliberações, com a finalidade de monitorar a eficiência de uso dos fatores de produção, procurando otimizar o desempenho desses fatores.

Pode-se dizer que a gestão de uma empresa rural está fadada diretamente a processos de tomada de decisão, nos quais se avalia a alocação de recursos escassos em diversas gamas de produção e rentabilidade, sob pressão de um ambiente de riscos e incertezas, que são características da atividade rural. Santos e Marion (1996), conforme citado por Lourenzani, Souza Filho e Bànkuti (2012), definem a missão do administrador rural como:

O principal papel do administrador rural é planejar, controlar, decidir e avaliar os resultados, visando à maximização dos lucros, à permanente motivação, ao bem-estar social de seus empregados e à satisfação de seus clientes e da comunidade (SANTOS e MARION, 1996, p. 16).

Cabe ao administrador rural encontrar meios para responder as questões essenciais do seu empreendimento: o que, quanto, como, quando e para quem produzir. As respectivas respostas podem ser encontradas adotando-se ferramentas de suporte à gestão que, embora pouco utilizadas em sistemas agropecuários, encontram-se amplamente difundidas em sistemas de produção industrial (LOURENZANI, SOUZA FILHO e BÀNKUTI, 2012).

Dessa maneira, a gestão e o empreendimento rural moderno se encontram alinhados com a demanda do mercado consumidor externo ou com um mercado interno mais exigente. Esse alinhamento requer maior flexibilidade para os ajustes necessários às novas demandas do mercado, apresentando equilíbrio entre os aspectos de capacitação gerencial, adequação tecnológica e desempenho econômico (NANTES \& SCARPELLI, 2007). 


\section{OREVER/:}

\section{Desafios do empresário rural em um modelo de gestão "estabelecimento rural- empresa" da atividade leiteira}

Primeiramente, a gestão do empreendimento rural compreende a coleta de dados, a geração de informações, a tomada de decisões e as ações que derivam dessas decisões, as quais, infelizmente, não são tratadas de forma satisfatória pela literatura nacional e internacional. Tem-se que os trabalhos existentes nessa área estão quase sempre restritos aos aspectos financeiros e econômicos do empreendimento rural, tratando, por exemplo, de custos, finanças e contabilidade, deixando de abordar com amplitude o leque de desafios encontrados pelo gestor do empreendimento rural (BORTOLINI, 2010, p. 14).

A gerência da produção agrícola, e não diferente a da atividade leiteira, é diferenciada e particularmente mais difícil de ser executada que nos demais setores e atividades da economia em geral. O equilíbrio entre a oferta e a demanda, em uma situação de oscilação de preços e produção, não é retomado simplesmente por uma decisão gerencial. Portanto, variáveis exógenas, não sujeitas ao controle de uma gestão eficiente, afetam diretamente as tomadas de decisões do empreendedor rural (BATALHA, 1997 apud BORTOLINI, 2010, p. 15).

Um dos grandes desafios é o gerenciamento das informações, sendo que Tofler (apud FREITAS et al., 1997) entende que a informação é mais importante do que fatores como terra, trabalho, capital e matéria-prima. Nantes \& Scarpelli (2007) destacam a importância do planejamento e do controle na gestão das propriedades rurais, na qual se faz morada também a gestão de informações.

Segundo Freitas et al. (1997), a competitividade do mercado exige dos envolvidos no processo respostas rápidas e eficientes, sendo, então, a informação sem dúvidas um importante, senão elementar, fator de diferenciação de competitividade. $\mathrm{O}$ adágio conhecido "informação é poder" deve ser complementado e enxergado como "informação é vantagem competitiva", haja vista que quem toma a melhor decisão é quem tem as melhores informações em mãos.

O intuito básico da gestão de informação é o de habilitar o produtor leiteiro a alcançar os objetivos estabelecidos, através do uso eficiente dos recursos disponíveis, que envolvem pessoas, materiais, equipamentos, tecnologia, recurso financeiro e a própria informação coletada (BORTOLINI, 2010).

O controle dos registros em um estabelecimento empresa-rural, sob o ponto de vista da administração, tem como objetivo oferecer subsídios para diagnosticar situações e realizar planejamentos eficazes, além de proporcionar possíveis adaptações ao longo 


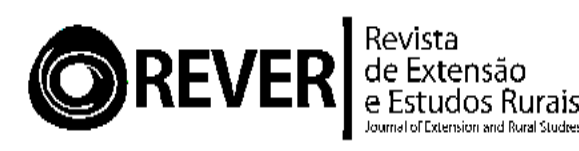

planejamento. Portanto, é de fundamental importância o produtor elaborar planos de ação embasados em informações confiáveis (ANDRADE, GONTIJO, FRANÇA, 2011).

As informações registradas em sistemas computadorizados são ferramentas importantes no monitoramento da atividade leiteira, já que permitem o controle através da alimentação constante de dados, que favorecem as tomadas de decisões, possibilitando a redução de custos e, como consequência, o aumento do desempenho da atividade (BEZZERA, FERREIRA, MARTINS, 2014).

Diante de tal desafio, os gestores rurais da atividade leiteira devem se precaver com algumas medidas e tomar notas observando determinadas áreas de gestão, entre as quais pode-se mencionar: Gestão de Produção; Gestão de Qualidade; Gestão da Tecnologia; Gestão de Custos; Gestão de Comercialização; e Gestão de Recursos Financeiros.

No âmbito da Gestão de Produção, destaca-se o planejamento das atividades produtivas, cujo objetivo é tornar a empresa rural mais eficiente e competitiva, dada a necessária tomada de decisões envolvida no processo de produção leiteira. Com isso, busca-se a maximização do controle dos fatores internos da unidade de produção rural, tal como a escolha da cultura a ser produzida (por exemplo, qual tipo de animal escolhido para obter determinada qualidade de leite), considerando-se, não somente características internas à unidade de produção leiteira, mas também levando em conta características externas a essa atividade (VILCKAS, 2005, apud BORTOLINI, 2010, p. 17).

Já sobre a Gestão de Qualidade, observa-se: indicadores de desempenho; feedback para avaliar a satisfação dos clientes; ações preventivas em geral; e identificação de potenciais problemas que ocorrem no processo produtivo do leite, na armazenagem ou no transporte (BORTOLINI, 2010).

$\mathrm{Na}$ atividade leiteira, a implantação de programas de qualidade apresenta como principal objetivo fornecer leite de qualidade ao consumidor final. Para alcançar tal escopo do programa, é importante adotar os necessários procedimentos de controle em todo o sistema de produção leiteira. Portanto, essa dinâmica envolve estabelecimentos rurais, laticínios, distribuição e varejo, além de aspectos de jurisdição do Estado no qual o estabelecimento se encontra (BRANDÃO, 2006, apud BIANCONI, GAMEIRO e SAES, 2007, p. 03).

No Brasil, sobre a qualidade do leite, destacam-se as Instruções Normativas (INs) 51/2002 e 62/2011, publicadas pelo Ministério da Agricultura, Pecuária e Abastecimento (MAPA, 2002, 2011, apud LOPES e WANDER, 2016, p. 18). Com a IN 62/2011, 


\section{OREVER}

segundo Dür (2012, apud LOPES e WANDER, 2016, p. 18), espera-se que o país assegure alimentos de melhor qualidade à população e alcance novos mercados no exterior. Contudo, o autor ressalta que para atingir isso, todos os elos da cadeia produtiva devem estar integrados em um esforço comum de produzir com qualidade.

A qualidade é um aspecto favorável frente à competitividade e à concorrência do segmento, bem como no que se refere à produção, uma vez que o pagamento pelo produto lácteo é baseado, entre outros critérios, principalmente na qualidade da matéria-prima ofertada (LOPES; WANDER, 2016, p.16).

De acordo com Koning (2004, apud LOPES e WANDER, 2016, p. 21), a Gestão da Tecnologia é empregada para que produtores de leite busquem aumentar a eficiência dos sistemas de produção, mediante a adoção de tecnologias de automação e pecuária de precisão. Para Hogeveen et al. (2004, apud LOPES e WANDER, 2016, p. 21), o maior impacto pode ser constatado na redução do tempo de produção e nos custos da atividade, por exemplo, quando da remoção e tratamento de dejetos ou alimentação em ordenha dos animais. Sendo assim, uma robotização dos sistemas de ordenha torna o processo mais flexível e menos laborioso.

Uma tecnologia bem empregada permite aos colaboradores do empreendimento não se prolongarem ordenhando os animais manualmente, sendo assim, permanecem mais tempo inspecionando o empreendimento e observando os animais, o que para os empresários rurais se torna um procedimento chave para detectar problemas precocemente, em função da maior disponibilidade de tempo para gerir sua atividade (BUTLER et al., 2012; SCHEWE E STUART, 2015 apud LOPES e WANDER, 2016, p. $18)$.

A robotização no processo de ordenha é uma tendência mundial e uma resposta aos aumentos dos custos, à escassez de mão de obra rural e à necessidade de melhoria da qualidade de vida e da rotina de trabalho. Os equipamentos disponíveis no mercado geram informações que permitem o entendimento da variabilidade individual dos animais, contribuindo para a aplicação dos conceitos de pecuária de precisão (LOPES \& WANDER, 2016).

Levando em conta a Gestão de Custos, sabe-se que a administração rural dispõe de ferramentas gerenciais adequadas às especificidades dos sistemas produtivos leiteiros, dentre as quais destacam-se os indicadores de desempenho financeiro e os sistemas analíticos de custeio da propriedade (BORTOLINI, 2010). 


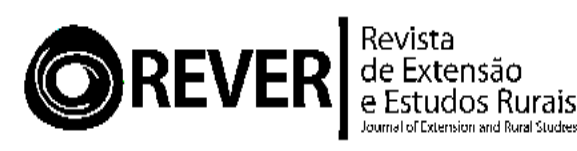

Para Gestão de Comercialização, o produtor leiteiro deve entender que está inserido em uma ou até várias cadeias de abastecimento e de negócios, que envolvem desde fornecedores até consumidores finais, passando pela produção, compra, gestão de materiais e vendas. A maneira como essa cadeia é planejada determinará o desempenho de todos os agentes pertencentes a ela (BORTOLINI, 2010).

No que se refere à Gestão de Recursos Financeiros, deve-se manter observação quanto aos custeios da atividade produtiva, aos subprojetos de investimentos em atividades de comercialização da produção leiteira e ao suprimento das necessidades durante o ciclo produtivo do leite (BORTOLINI, 2010).

Os desafios enfrentados pela Gestão de Recursos Financeiros são: planejar esquemas financeiros ou de custeios; analisar investimentos; compreender a produção visando ao melhoramento do processo produtivo; alocar o marketing - quando, então, identifica-se tendências de mercado -; além de buscar alternativas estratégicas para escoamento da produção; e analisar indicadores de desempenho. Todos esses aspectos são auxiliares nas tomadas de decisões em uma gestão moderna da atividade leiteira (ANDRADE, GONTIJO, FRANÇA, 2011).

Conforme citado por Crepaldi (2005 apud DE PARIS et. al., 2013, p. 08), o gestor deve estar sempre atento às tarefas de planejar, organizar, direcionar os subalternos diretos e orientar o controle administrativo, além de sempre apresentar planos, como orçamentos de controle, que permitam acompanhar o andamento da atividade leiteira.

Utilizando tais ferramentas dentro de um modelo de gestão moderna, o produtor leiteiro adquire uma visão sistêmica do seu empreendimento, identificando a importância do acompanhamento por um método eficiente, gerando tomadas de decisões mais precisas para sua produção de leite.

De maneira geral, com o advento da globalização e o mercado cada vez mais competitivo, as empresas necessitam adotar estratégias que agreguem valor aos seus produtos, criando vantagens competitivas perante seus concorrentes. Com a pecuária de leite não é diferente; além das ferramentas zootécnicas utilizadas para a melhoria do plantel existente, os produtores devem alcançar melhores resultados através do aperfeiçoamento da gestão de suas propriedades, utilizando ferramentas administrativas, dentre as quais se destaca o planejamento estratégico, no qual se definem objetivos, metas e estratégias, que garantem um crescimento focado, com maior aproveitamento dos recursos e maximização dos resultados, enfrentando, assim, os desafios de gestão da propriedade com maior clareza (OHI, 2010, apud DE PARIS et. al. 2013, p. 10). 


\section{OREVER}

Portanto, utilizar as ferramentas de gestão disponíveis sob orientação capacitada, conhecendo cada realidade singular, planejar ações, estabelecendo metas e objetivos e avaliando periodicamente os resultados, e utilizar as tecnologias sustentáveis disponíveis no mercado, certamente aumentam a capacidade dos fatores de produção, obtendo, então, maior lucratividade e melhor rentabilidade da pecuária leiteira.

É inaceitável que o produtor de leite, no atual cenário de mercados globalizados, não possua informações acerca do próprio estabelecimento, para construir um adequado ambiente de gestão em busca da eficiência. Contudo, é imprescindível, para a continuidade sustentável de sua atividade leiteira e avaliação de desempenho geral, planejar periodicamente uma gestão em busca de melhorias para o estabelecimento empresa-rural (BORTOLINI, 2010).

\section{O entendimento da gestão e seus desafios}

O produtor rural desenvolve suas atividades agropastoris entre os mercados de insumos e produtos, assumindo os riscos de clima, baixos preços de seus produtos e mudanças nas políticas econômicas. Percebe-se que a administração rural é uma área do conhecimento elementar para não só auxiliar a transição de um empreendimento rural tradicional para um empreendimento rural moderno (NANTES \& SCARPELLI, 2007), mas também melhor oportunizar a gerência do ponto de vista de processos adotados, considerando as especificidades da atividade leiteira.

O princípio básico da produção é que todo o sistema se mantenha em equilíbrio; os produtores que não conseguem inovar ou ajustar as suas estruturas tecnológicas e o custo de produção estarão com seu negócio inviabilizado (OLIVEIRA et al., 2007). Portanto, é imprescindível que os gestores se profissionalizem, tornem-se empreendedores munidos de informações e estejam atentos às mudanças do mercado. Lembrando que quando a propriedade rural é vista como uma empresa, considera-se um desafio tornar os produtos mais eficientes e competitivos (FIRETTI; RIBEIRO, 2001).

Com o avançar do presente estudo, percebe-se que a propriedade rural é uma unidade de análise que, alinhada à ciência administrativa e zootécnica, pode alavancar o nível de produção e proporcionar mais clareza na tomada de decisão como um todo. Há uma elementar necessidade de gerir a fusão entre as áreas do conhecimento mencionadas, para se obter uma visão sob perspectiva sistêmica do empreendimento, a fim de proporcionar firmeza ao empreendedor rural e mais clareza nas tomadas de decisão. 


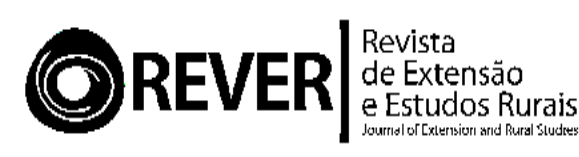

Outro apontamento que foi considerado elemento chave da discussão é o de que o produtor leiteiro tem que se reconhecer como empreendedor rural, ou seja, tal atividade econômica requer também habilidades de gestão, devendo-se projetar o estabelecimento rural como uma empresa rural, além de se considerar um empreendedor do ramo leiteiro.

Fassio, Reis e Geraldo (2006) realizaram pesquisa em propriedades leiteiras de Minas Gerais, da qual retirou-se um estudo de desempenho técnico e econômico que analisou os resultados econômicos, os indicadores de produção e produtividade, os índices zootécnicos e a disponibilidade financeira, os insumos e os serviços. O estudo chegou em evidências de que se deve modernizar e profissionalizar a administração dos estabelecimentos, qualificando produtores e mão de obra, através do uso de informações técnicas e gerenciais, que permitem maximizar os fatores produtivos do ambiente.

Em uma pesquisa feita no interior do estado do Paraná, contatou-se que dos $61 \%$ de produtores que realizam atividades de coleta e registro de dados, $95 \%$ não revertiam em análise para subsidiar o processo de tomada de decisão. O aspecto mais relevante se refere ao fato de que, entre os $39 \%$ que não realizam coleta e registro dos dados, alguns declararam que não o fazem por falta de tempo e hábito e porque não enxergam importância nos processos de controle de dados (QUEIROZ \& BATALHA, 2003). Dessa forma, identifica-se uma necessidade de coleta de dados, tratamento e utilização de informações, para se atingir um processo de gestão eficiente e eficaz.

Um outro estudo, desenvolvido no Sul do Piaú, aponta que, da amostra de propriedades rurais estudadas, ninguém mencionou o uso de controle de registros por meio de livros caixa ou método computacional, verificando-se a ineficiência administrativa e gerencial dos produtores (BEZZERA, FERREIRA, MARTINS, 2014).

Segundo Hoffmann et al. (1981):

Os objetivos mais importantes dos registros agrícolas devem ser para avaliar o financeiro e a determinação de seus lucros e prejuízos durante um período determinado da empresa rural, fornecendo, assim, a base exigida para fazer um diagnóstico do empreendimento e elaborar seu planejamento de forma eficaz (Hoffmann et al, 1981).

Os registros consistem em capital imprescindível para a melhoria da saúde gerencial da propriedade rural. Entende-se que o registro de informações passou a ser considerado um alto recurso e um capital precioso para o empreendimento leiteiro, equiparando-se aos recursos de produção, materiais e financeiros, o qual, através de ferramentas auxiliares, pode e deve ser instrumentalizado pelo gerenciador em seu empreendimento rural. 


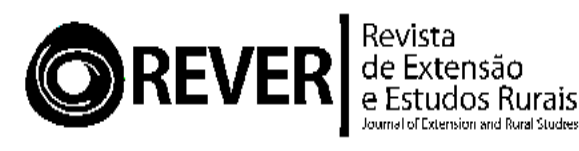

Sinaliza-se, portanto, haver a possibilidade de maiores ganhos e de melhorias nos estabelecimentos de produção leiteira com uma eficiente gestão das informações. A geração de indicadores padrões facilita e agiliza a tomada de decisões do empreendedor, com um modelo de gestão moderna frente aos tradicionais.

Pode-se observar ainda que, mesmo aderindo à coleta e à gestão de informações, a medição do desempenho merece atenção especial em razão da sua importância para o desenvolvimento da função gerencial. Considerado algo complexo e difícil, a medição de desempenho é capaz de fornecer informações de suma relevância para a tomada de decisão na busca da alta qualidade e da sustentação do empreendimento no ramo de atividade leiteira.

Percebe-se que a adequação da produção aos padrões de exigência do mercado consumidor é condição necessária para a inserção de um empreendimento leiteiro em um modo produtivo coordenado, alimentando, assim, positivamente as análises de desempenho "dentro da porteira".

Entendeu-se que é impossível melhorar a qualidade do leite depois que ele deixa a fazenda (SANTOS E FONSECA, 2007 apud BIANCONI, GAMEIRO e SAES, 2007, p. 06) e, também, que esta está relacionada diretamente ao valor pago pelo produto final, além de proporcionar maior competitividade e confiabilidade no mercado consumidor.

Produzir leite a baixo custo e também com qualidade requer gestão eficiente do empreendimento, implicando a adoção de controles zootécnicos, administrativos e econômicos. Sendo assim, avaliar o desempenho da pecuária leiteira permite identificar possíveis entraves de gestão rural ao seu desenvolvimento, além de descobrir falhas no processo administrativo, fornecendo, assim, subsídios à tomada de decisões do agricultor que persegue a maximização da utilização de recursos disponíveis.

\section{Considerações finais}

Em tempos atuais, de economia global, o setor agrícola passa por algumas transformações, sendo exigido das organizações envolvidas no processo de produção efetivar uma gestão mais eficiente, sustentável e inovadora. Ou seja, deve-se ter uma visão empreendedora dos negócios e atividades para sobreviver ao longo do tempo e reviver prosperidade econômica, além de alcançar prestígio no ramo de atividade.

Planejamento, organização, comando, execução, controle, análise e revisão de objetivos e metas são essenciais para a gestão eficiente de um estabelecimento de produção rural leiteira. Portanto, uma propriedade que trabalha com produção de leite 


\section{OREVER}

como fonte de renda deve ser vista como uma empresa rural e, como qualquer outro empreendimento, precisa ser economicamente viável para garantir sua sobrevivência.

Práticas adequadas de gestão são essenciais para o produtor ter sucesso em seu empreendimento. Nesse sentido, cabe a ele o planejamento da produção, a organização do estabelecimento e o controle de todo o processo e atividades desempenhadas. Ainda, deve-se anotar e controlar as etapas produtivas que diariamente ocorrem na propriedade, para fins de controles zootécnicos e administrativos, sendo que, após analisadas e somadas às informações de "fora da porteira", tais anotações servirão de parâmetro confiável para a melhor tomada de decisão em tempos atuais, de informações instantâneas. Esses dados são vistos como um recurso altamente diferencial, voltado para o uso máximo da capacidade instalada na propriedade, além de buscarem melhor rentabilidade da atividade leiteira, auxiliando na superação das deficiências que bloqueiam o seu desenvolvimento.

Elementos advindos de variadas áreas do conhecimento, mencionados no presente estudo, dão suporte à gestão rural e devem ser absorvidos como elementares atribuições para que o empreendimento rural se torne um modelo de sucesso no ramo de atividade leiteira. Ou seja, o gestor rural deve atender à chamada globalizada e se adaptar a um modelo de gestão moderno, a fim de que alcance os objetivos do seu planejamento de produção.

Mais importante que produzir é produzir com organização, controle e conhecimento absoluto e total do processo que está sendo executado, ou seja, é necessário não inibir ou subestimar as informações que pertencem ao empreendimento rural, pois, sem contar com elas, o proprietário já está em desvantagem no ramo de atividade leiteira. Aliás, tal atributo deveria ser o elemento chave para propulsionar e alçar o gestor rural em direção à gestão moderna de seu empreendimento.

\section{Referências bibliográficas}

ANDRADE, A. L. S.; GONTIJO, C. M.; FRANÇA, P. B. Gestão do Agronegócio Familiar: Estudo de Caso da Fazenda Paraíso. Revista Brasileira de Gestão e Engenharia, Minas Gerais, n. 3, p. 01-19, jan. /jun. 2011.

ARAÚJO, L. M. Avaliação técnica e econômica da atividade leiteira da fazenda boa esperança. 2016. 74 f. Trabalho de Conclusão de Curso (Bacharel em Zootecnia) Universidade Federal de São João Del Rei campus Tancredo de Almeida Neves, São João Del Rei, 2016. 


\section{OREVER|}

BATEMAN, T. S.; SNELL, S. A. Administração: construindo vantagem competitiva. São Paulo: Atlas, 1998. 539 p.

BNDES, Banco Nacional do Desenvolvimento. Produção Leiteira no Brasil, Agropecuária, BNDES Setorial 37, p. 371-398, mar. 2009. Disponível em: https://web.bndes.gov.br/bib/jspui/bitstream/1408/1514/1/A\%20mar37_09_Produ\%C3 \%A7\%C3\%A3o\%201eiteira\%20no\%20Brasil_P.pdf Acesso em: 17 out. 2018.

BIANCONI, L. L.; GAMEIRO, A. H.; SAES, M.S. M. Um Modelo De Gestão E Avaliação De Procedimentos Operacionais Na Pecuária Leiteira. In: XLI CONGRESSO DA SOCIEDADE BRASILEIRA DE ECONOMIA, ADMINISTRAÇÃO E SOCIOLOGIA RURAL, 2007, Londrina. Anais..., 2007.

BORTOLINI, G. Gestão Da Pequena Unidade Familiar Produtora De Leite: Uma análise do modelo de gestão através da compreensão da unidade de produção. 2010. 57 f. Trabalho de Conclusão de Curso (Especialização em Gestão do Agronegócio) Universidade Vale do Rio Sinos, São Leopoldo, 2010.

CASSANEGO JR, Paulo et al. Análise da Social Netchain no Aglomerado Produtivo do Leite em Santana do Livramento (RS). Revista de Extensão e Estudos Rurais, Viçosa, MG, v. 7, n. 1, p. 373-397, jul. 2018. ISSN 2359-5116. Disponível em: https://periodicos.ufv.br/ojs/rever/article/view/3350 Acesso em: 06 maio 2019.

CONAB, Companhia Nacional de Abastecimento. Conjuntura Mensal - Leite $e$ Derivados, 2016.2 Disponível em: http://www.conab.gov.br/OlalaCMS/uploads/arquivos/16_04_12_14_04_46_leite_marc o_2016.pdf Acesso em: 17 out. 2018.

CONAB, Companhia Nacional de Abastecimento. Conjuntura Mensal - Leite $e$ Derivados, jul. 2017. Disponível em: http://www.conab.gov.br/OlalaCMS/uploads/arquivos/17_08_09_18_22_07_leite_julho _2017.pdf Acesso em: 17 out. 2018.

DA SILVA et al. Avaliação dos indicadores zootécnicos e econômicos em sistemas de produção de leite. Revista de Política Agrícola, Brasília, n. 1, v. 24, p. 62-73, jan./fev./mar. 2015.

DE PARIS, M. et al., Gestão em Pequenas Propriedades Leiteiras Na Região Sudoeste do Paraná Como Estratégias para o Desenvolvimento da Atividade. In: CONGRESSO VIRTUAL BRASILEIRO DE ADMINISTRAÇÃO, IX, 2013, Anais... 2013.

FASSIO, Levy Heleno; REIS, Ricardo Pereira; GERALDO, Luiz Gonzaga. Desempenho técnico e econômico da atividade leiteira em Minas Gerais. Ciênc. agrotec., Lavras, v. 30, n. 6, p. 1154-1161, dez. 2006. Disponível em http://www.scielo.br/scielo.php?script=sci_arttext\&pid=S141370542006000600018\&lng=pt\&nrm=iso. Acesso em: 06 maio 2019.

FORMIGONI, Ivan. Indústria de lácteos brasileira: crescimento e importância, mar. 2017. Disponível em: http://www.foodnewsoficial.com.br/gestao-e-mercado/industriade-lacteos Acesso em: 17 out. 2018. 


\section{OREVER/|}

FREITAS, H.; et al. Informação e decisão: sistemas de apoio e seu impacto. 1997. Porto Alegre: Ortiz, 214p.

GODINHO, Ricardo. Ferreira. A gestão de empresas rurais, jun. 2015. Disponível em: https://www.milkpoint.com.br/radar-tecnico/gerenciamento/a-gestao-de-empresasrurais-95522n.aspx Acesso em: 17 out. 2018.

HOFFMANN, R. et al. Administração da empresa agrícola. 3.ed. 1981. São Paulo: Livraria Pioneira. 325p.

IBGE, Instituto Brasileiro de Geografia e Estatística. Tabela 94 - Vacas Ordenhadas. Disponível em: https://sidra.ibge.gov.br/tabela/94 Acesso em: 17 out. 2018.

LOPES, Dias. Lopes.; Wander, Alcido. Elenor. Percepção da Competitividade do Segmento de Produção de Leite no Município de Morrinhos, Estado De Goiás, 2015. Disponível em: http://www.iea.sp.gov.br/ftpiea/publicacoes/ie/2016/tec2-0616.pdf Acesso em: 17 out. 2018.

LOPES, M. A. et al. Custo leite para windows: software de controle de custos para a pecuária leiteira. Revista Brasileira de. Zootecnia Viçosa, v. 29, n. 5, p. 1504-1510, out. 2000. Disponível em: http://www.scielo.br/scielo.php?script=sci_arttext\&pid=S1516-

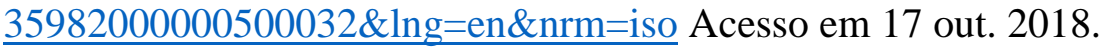

LOURENZANI, Wagner Luiz; SOUSA FILHO, Hildo Meirelles de; BÀNKUTI, Ferenc. Istvan. Gestão da Empresa Rural - Uma abordagem sistêmica. Disponível em: http://www.gepai.dep.ufscar.br/pdfs/1102012100_LourenzaniSouzaBankutipdf Acesso em: 17 out. 2018.

MACHADO, Paulo. Fernando; MENEGHINI, Rafael. Cedric. Möller. Gestão em propriedades rurais: por onde começar, abr. 2011. Disponível em: https://www.milkpoint.com.br/radar-tecnico/gerenciamento/gestao-em-propriedadesrurais-por-onde-comecar-71253n.aspx Acesso em: 17 out. 2018.

MAPA. Ministério da Agricultura, Pecuária e Abastecimento. Plano Mais Pecuária / Assessoria de Gestão Estratégica. Brasília: MAPA/ACS, 2014.

MARCONI, M. A.; LAKATOS, E. M. Metodologia do trabalho científico. São Paulo: Editora Atlas, 1992. 4 a ed. p.43 e 44.

MARTINS, Z. L. Custos da Produção Leiteira da Agricultura Familiar em Colorado do Oeste - RO. 2014. 42 f. Dissertação (Mestrado em Produção Animal), Universidade Camilo Castelo Branco - UNICASTELO, Descalvado - SP.

NANTES, J. F.D.; SCARPELLI, M. Elementos de gestão na produção rural. In: BATALHA, Mário O. (org.). Gestão Agroindustrial. 3.ed. v.1. São Paulo: Atlas, 2007. p.629-664. 


\section{OREVER|}

QUEIROZ, T.R., BATALHA, M. O. Gerenciamento das pequenas propriedades agrícolas familiares na Região de Araraquara e São Carlos. In: XLI CONGRESSO BRASILEIRO DE ECONOMIA E SOCIOLOGIA RURAL, 2003, Juiz de Fora. Anais..., 2003.

BEZERRA, Leilson Rocha; FERREIRA, Raimundo Ribeiro; MARTINS, Isnarde Souza. Avaliação tecnológica de sistemas de produção de leite bovino. Revista de Extensão e Estudos Rurais, Viçosa, MG, mar. 2015. ISSN 2359-5116. Disponível em: https://periodicos.ufv.br/ojs/rever/article/view/3311 Acesso em: 06 maio 2019.

SEAB - Secretaria de Estado da Agricultura e do Abastecimento. Leite - Análise da Conjuntura Agropecuária, ano 2015/2016. Disponível em: http://www.agricultura.pr.gov.br/arquivos/File/deral/Prognosticos/2016/bovinocultura de_leite_2016.pdf Acesso em: 17 out. 2018.

SILVA, A. G. Gerenciamento Rural e Gestão da Qualidade Total em Empresas Rurais Produtoras de Leite. 190 f. Tese (Programa de Pós-Graduação em Economia Rural) Universidade Federal de Viçosa, Viçosa, 2000.

VALLÉ S.A. Fazenda Produtora de Leite ou Empresa Produtora de Leite. Disponível em: https://www.youtube.com/watch?v=-xYIqIBCk5o Acesso em: 17 out. 2018.

WILBERT, E.; et al. Estratégia competitiva de uma indústria de laticínios no mercado leiteiro brasileiro: uma visão baseada em recursos. In: II SIMPÓSIO INTERNACIONAL DE INOVAÇÃO EM CADEIAS PRODUTIVAS DO AGRONEGÓCIO, 2016, Caxias. Anais..., 2016.

ZOCAAL, Rosangela. - Centro de Inteligência do Leite - EMBRAPA. Panorama do Leite online, ano 6, n.64, mar. 2012. Disponível em: http://www.cileite.com.br/sites/default/files/Conjuntura_2012_03.pdf Acesso em: 17 out 2018.

Balde Branco: alguns números do leite, set. 2016. Disponível em: http://www.baldebranco.com.br/alguns-numeros-do-leite Acesso em: 17 out 2018. 